\title{
Integration of Chinese Publications
}

Miss Cressaty, formerly librarian of the von KleinSmid Library of World Affairs, University of Southern California, is now librarian, College of Osteopathic Physicians and Surgeons, Los Angeles.

$\mathrm{T}$ HE THOUght of devising a system of classification, to see it grow, and to modify it has tantalized many a librarian. It would be pleasant to sit in an ivory tower and have the time to meditate on a classification for a body of knowledge. The task would have its reward in the exactness of the fit of the scheme to the chosen group of books and subject. However, most libraries cannot afford the specialists and provide the continuity of staff that special schemes entail.

Useful articles have been written about the classification of special collections. However, applying a special classification scheme to books just because they are in a foreign language may result in considerable expense. Can books in a foreign language be classified according to the one used by the library? Is a special scheme worth the effort? These are questions to ponder. There is no entirely right answer; it depends too much on the library's needs and resources.

Articles on the classification and cataloging of publications in Chinese which have appeared recently in professional publications have involved special schemes of classification and the maintenance of a staff with a reading knowledge of Chinese. This discussion will present a simpler method of procedure. In the von KleinSmid Library of World Affairs at the University of
Southern California, there is a collection of approximately 500 titles in the Chinese language. The subjects vary considerably from the classics (belles lettres, philosophy, history, etc.), archaeology (Chinese inscriptions on bone and bronze), and art to education and government reports. The publication dates range from 1600 to date. This wide range of subject matter and length of period covered presented a problem. Since Chinese characters have undergone many changes from the time they were inscribed on bones, a knowledge of presentday Chinese characters would not be sufficient. And modern Chinese publications are often done in characters that imitate ancient script.

Since there was not available at that time (1938) a staff member with a knowledge of both Chinese and cataloging, it was decided to secure the services of a graduate Chinese student, Vincent Shih, who was studying for a doctorate in philosophy. Mr. Shih had a knowledge of both ancient and current ideographic symbols and also a proficiency in Chinese calligraphy. This is an important quality since the Chinese are critical of how the characters are written.

For several hours each afternoon, Mr. Shih would dictate the transliteration of the title pages to the cataloger. When the subject matter was not comparable immediately to the English, Mr. Shih would give further information in order to assist in the classification of the book. From this the cataloger prepared a draft of the main entry card. Mr. Shih checked the transliteration (Wade-Giles system), translation, 
and prepared the card in Chinese.

The form followed on the English cata$\log$ cards was the usual one with the author's name inverted (inverted in the English sense since the Chinese write the last name first and then the first name; the first name is hyphenated frequently with the middle name) and entered in Roman type. The title, place, publisher and date were entered in the body of the card. Generally the collation was given in detail since Chinese material often has many prefaces, introductions, etc. that are numbered separately. However, when the collation became too involved the total pagination was indicated in brackets and the note "various pagings" used. Since much of the material is rare or had been issued in several editions, it was thought best to indicate collation in detail when possible.

That the text is Chinese was mentioned in a note. Another note gave the translation of the title. Other facts, such as foreedge painting, relation to other editions, and various names of the author were given in notes. This meant an extremely full card but it was believed that the intrinsic value of the information far outweighed the time of typing and space. It should be explained that pica type was used; if elite type had been used, the additional space could have been used to an advantage by having the Chinese characters on each card. These characters could be placed on the reverse of the card.

It must be understood that Romanization to the Chinese is almost like another language. The Chinese characters are much easier for anyone with a knowledge of Chinese to read. The Romanization was used because of the time element and because it was hoped that the catalog would be used by students who were learning Chinese. There was even in 1938 a goodly number of students studying Chinese at the
University. Some of them planned to use it in the foreign service, some in foreign trade, and others just because they wanted to learn Chinese.

For the purposes of the collection, the Library of Congress subject headings were used. Each entry had an added entry "Chinese books" or "Chinese periodicals"; or, really two added entries since one card was in the Romanized type and the other in Chinese script. On the reverse of the Chinese card the Romanization of the author's name and title were typed. (This was for the benefit of the cataloger.) Under the heading "Chinese books" there were two divisions - the Chinese cards filed by stroke and the Romanized arranged alphabetically. This provides a file for those who read Chinese and one for those who do not. During World War II these files were used intensively by government officials. Title cards using the Romanized title were made. When the publication was a translation of a foreign work, the original title was used also for an entry.

As for a classification system, the Library of Congress schedules were used. The value of a separate scheme was considered carefully. However, it would have several disadvantages. First of all, it would not conform to the scheme used in the library. There would be the confusion caused by a different type of notation. By using the Library of Congress classification, the English edition of Sun Yat-sen's Three People's Principles could be placed next to the Chinese. Of course, some libraries may want to shelve the Chinese material separately, but in other libraries it may be advantageous to have editions in various languages shelved together.

The Stanford University Libraries use the Dewey Decimal Classification, and the Library of the Ministry of Education uses the Nanking system of book numbers. An- 
other scheme is used at the University of California and still another at Claremont Colleges. In these libraries, there were other factors that influenced the decisions.

While the Oriental Department of the Library of Congress is very helpful in supplying information, it would solve more problems if its cards were available for distribution. Or, if the Harvard Yenching Institute's A Classical Catalogue of Chinese Books were further along; (only three volumes have been issued of the intended IO or 12); if each volume were indexed; and, if more information were given for each entry, its classification scheme might surmount the obstacle of being distinct from that used for the remainder of the collection in the library. Since only the largest university libraries have room for the HarvardYenching card catalog, its use is not considered.

It would then seem that for the smaller, departmental, or more specialized library it would be better to classify and catalog the Chinese publications in accordance with the accepted procedure for other books. How many libraries have adopted a special scheme for German or French books? Or, for Arabic or Hebrew since these involve different scripts? True, they are often shelved in special sections, but this is done generally when the open shelf system is used and to permit browsing.

The cataloger should consider carefully the purpose of the Chinese collection in the particular library. The disadvantages of an elaborate system are many. And, provided there is someone who reads Chinese and can make a catalog in Chinese alone, will not its use be restricted to his hours and to those who read Chinese?

In contrast, the simpler scheme as outlined allows any librarian to go to the catalog and to turn to the same subject heading as for books in English and to find how many books there are in Chinese on a given subject. It permits the research worker to find the book he wants and if he does not read Chinese he can have it translated.

While the simplest method of cataloging is the one that conforms to the one in use in the library, some attention should be given Chinese tradition in the matter of binding. In the von KleinSmid Library, ivory clips were secured from China and cases made of card board and cloth were fastened with them. These were copied from Chinese cases. Blue muslin was used to cover most of the cases, since blue symbolized wisdom.

While some very excellent classification schemes and cataloging routines have been developed for special subjects, it would seem that books in a foreign language and script can be classified and cataloged in the same manner as other books in the library's collection. University libraries with large collections of foreign books will, no doubt, continue to devise new schemes and smaller libraries benefit from the results. However, until such schemes are proven to fill the needs of the smaller libraries, the use of the classification scheme and catalog rules already in use will integrate the foreign books in the collection and help to make them more accessible. While special schemes have many advantages, the temptation to devise one should be governed by the permanence of the staff, its size, the number of specialists available, and the necessity to inform the general staff of the ramifications of the special classifications. Publications in Chinese as well as books in other languages can be integrated into the library's collection and classification scheme. 